\title{
Skeletal abnormalities in humpback whales Megaptera novaeangliae stranded in the Brazilian breeding ground
}

\author{
Kátia R. Groch ${ }^{1,2, *}$, Milton C. C. Marcondes ${ }^{1}$, Adriana C. Colosio ${ }^{1}$, \\ José Luiz Catão-Dias ${ }^{2}$ \\ ${ }^{1}$ Instituto Baleia Jubarte, Caravelas, Bahia 45900-000, Brazil \\ ${ }^{2}$ Laboratório de Patologia Comparada de Animais Selvagens, Departamento de Patologia, \\ Faculdade de Medicina Veterinária e Zootecnia, Universidade de São Paulo, São Paulo-SP 05508-270, Brazil
}

\begin{abstract}
Skeletal tissues of 49 humpback whales Megaptera novaeangliae that stranded between 2002 and 2011 along the Abrolhos Bank seashore and its adjacent waters in Brazil were studied. Twelve $(24.5 \%)$ animals presented pathological changes in one or more bones. Degenerative changes and developmental malformations were most frequent $(10.2 \%$ each), followed by inflammatory/infectious and traumatic lesions (8.2\% each). Infectious diseases led to severe lesions of the caudal vertebrae of 2 whales. In one of these individuals, the lesions involved 6 caudal vertebrae, leading to ankylosis of 3 vertebrae. Degenerative changes were observed in the vertebral columns of 3 animals, involving the joints of 13 ribs of 1 individual, and in the humerus of 1 whale. Traumatic lesions, such as osseous callus in the ribs, were observed in 4 animals. In 1 whale, the rib showed severe osteomyelitis, possibly resulting from the infection of multiple fractures. Developmental abnormalities such as spina bifida on 3 cervical vertebrae of 1 whale, fusion of spinal processes on thoracic vertebrae of 1 individual and fusion of the first 2 ribs unilaterally or bilaterally in 4 animals were found. Chronic infectious conditions found in the axial skeleton may have restrained spinal mobility and had detrimental effects on the general health of the animals, contributing to stranding and death. To our knowledge, this is the first systematic study on skeletal lesions in stranded humpback whales.
\end{abstract}

KEY WORDS: Cetacean · Skeletal pathology · Infectious disease · Osteomyelitis · Spondylodiscitis · Degenerative disease $\cdot$ Spondyloarthrosis $\cdot$ Developmental abnormality

- Resale or republication not permitted without written consent of the publisher

\section{INTRODUCTION}

Every winter, humpback whales Megaptera novaeangliae of the southwestern Atlantic Ocean population migrate from feeding grounds in Antarctic waters to tropical waters on the Brazilian coast to breed and calve. They concentrate mainly in the Abrolhos Bank $\left(16^{\circ} 40^{\prime}-19^{\circ} 30^{\prime} \mathrm{S}, 37^{\circ} 25^{\prime}-39^{\circ} 45^{\prime} \mathrm{W}\right)$, an enlargement of the continental shelf (Andriolo et al. 2006). A total of 9330 whales was estimated for the Brazilian coast in 2008 (Wedekin et al. 2010). Strand- ings commonly occur; from 2002 until 2011, there were 153 single stranding cases along the Abrolhos Bank seashore and adjacent waters. In $91 \%$ of these cases, the whale died at sea and was washed ashore (Instituto Baleia Jubarte [IBJ] unpubl. data).

Full necropsy and histopathological analysis of soft tissues are often impaired by decomposition state and necessary logistics related to the size of the animal. Analysis of skeletal changes, which are relatively resistant to decomposition, may provide valuable information on the life history and pathological conditions 
of the animal. However, information on skeletal abnormalities in humpback whales is scarce: 5 single cases have been reported (Stede 1994, Paterson \& Van Dyck 1996, Kompanje 1999, Félix et al. 2007, Hellier et al. 2011). Stede (1994) reported osteoperiostitis ossificans hypertrophicans in the caudal vertebra of a humpback whale calf from Germany. Paterson \& Van Dyck (1996) described a humpback whale fetus from Australia with injuries consistent with trauma during parturition, such as bilaterally fractured ribs and superficial focally extensive cystic osseous lesions associated with periosteal new bone formation in the supra-orbital region. Hellier et al. (2011) reported the presence of a remodeled lesion ventrally in the maxilla, possibly related to trauma to the baleen plates and/or adjacent soft tissue in a 13.5-m-long humpback whale. The animal also presented bony bridging in the left aspect of the neural arches of 2 cervical vertebrae, and multiple localized areas of reactive bone growth in the vertebral column (Hellier et al. 2011). Spondyloarthritis was suspected to occur in caudal vertebrae of a specimen from Denmark (Kompanje 1999). Severe infectious spondylitis affected 7 lumbar and 4 caudal vertebrae of a 7.25-m-long humpback whale from Ecuador (Félix et al. 2007). The goal of the present study was to investigate the occurrence of skeletal pathologic processes in humpback whales, as well as to evaluate their potential to compromise health and contribute to the stranding event or death.

\section{MATERIALS AND METHODS}

The total coastal area covered consists of approximately $500 \mathrm{~km}$ between the municipalities of Belmonte, State of Bahia (15 $\left.44^{\prime} \mathrm{S}, 38^{\circ} 53^{\prime} \mathrm{W}\right)$, and Santa Cruz, State of Espírito Santo $\left(20^{\circ} 00^{\prime} \mathrm{S}, 40^{\circ} 09^{\prime} \mathrm{W}\right)$, Brazil, including the coastline of Abrolhos Bank and Royal Charlotte Bank.

One hundred and fifty-three humpback whales were found stranded from 2002 until 2011 (IBJ unpubl. data). For each animal, a specimen number was issued and information regarding date and location of stranding, body length and sex were recorded. Bones from 49 animals that stranded alive and subsequently died, or were found dead, were examined in situ. Some examinations were performed opportunistically when the team was helping section carcasses to facilitate removal. Bones were cleaned during dissection and the remaining soft tissue was removed through maceration in water and/or washing and drying. A rib with extensive bone outgrowth and remodeling
(Specimen 256) was radiographed and scanned using computed tomography (CT) at $7 \mathrm{~mm}$ slice thickness, $80 \mathrm{kV}$ and $240 \mathrm{~mA}$, with a 2-channel helical scanner (GE Medical Systems) at Centro de Imagem São Paulo in Teixeira de Freitas, Bahia. Images were processed using K-PACS (www.k-pacs.net) and Vitrea (www.vitalimages.com) software.

All bones found with pathological changes were digitally photographed, collected along with samples of apparently normal bones, identified by specimen number and archived at IBJ in Caravelas, Bahia. The exceptions are the skeletons of 3 animals that are currently on exhibition at the IBJ, in Praia do Forte, Bahia (Specimen 122), and at the Frans Krajcbergof Ecological Museum, in Nova Viçosa, Bahia (Specimens 242 and 334). Due to field logistical difficulties, only 2 ribs with the most severe lesions were collected from Specimen 358, which had pathological changes in 13 ribs; the remaining ribs were photographed at the stranding site.

Age classes were assigned based on the standard body length following the classification used in Mazzuca et al. (1998), i.e. calves < 8 m, juveniles 8-11.6 m and adults $>11.6 \mathrm{~m}$. Estimated length based on measurements of incomplete carcasses was used to estimate maturity whenever possible. Sex was determined by gross examination at the time of stranding or by genetic analysis of skin (Engel et al. 2006, Cypriano-Souza et al. 2009).

In adult animals, bones were removed from the carcass for examination. Vertebrae of younger animals had most soft tissue removed and the vertebral body and the ossified portions of the arch and transverse processes were examined. Intervertebral disks were inspected for narrowing of the disc space between the 2 vertebrae, disk protrusion and abnormal ossification. The gross examination of each bone included assessment of erosion, cavities or eburnation on joint surface, exostosis, anomaly, fusion and fracture. Pathological changes were further classified as resulting from developmental malformation, and degenerative, infectious and inflammatory, or traumatic lesion. In the present study, pathological conditions were categorized based on what was considered the nature of the early lesion or pathogenesis. For degenerative and inflammatory diseases, the classification proposed by Thompson (2007) and Kompanje (1999) was used.

During necropsies, dissection of thoracic and abdominal cavities was prioritized. Skulls were occasionally found a few meters apart from carcasses, partially buried in sand, with post mortem fractures of rostrum or damages due to shark scavenging. 
Examination was limited to the position that they were found in (usually with dorsal side down) and precluded a reliable assessment; thus, skull examination was not included in this study.

\section{RESULTS}

Of the 153 whales that stranded on the Abrolhos and Royal Charlotte Banks region between 2002 and 2011, 49 animals were examined for skeletal disorders. Of these, $22.4 \%(11 / 49)$ were females, $28.6 \%$ (14/49) were males and $49 \%$ (24/49) whales were of undetermined sex; $38.8 \%$ (19/49) were calves, $20.4 \%$ $(10 / 49)$ were juveniles, $26.5 \%$ (13/49) were adults and $14.3 \%(7 / 49)$ were of undetermined age (Table 1).

Pathological changes were observed in $24.5 \%$ $(12 / 49)$ of the examined animals. Table 2 shows incidence by skeletal region. In the vertebral column, $28.6 \%(4 / 14)$ of the individuals presented lesions in the cervical region, $10 \%(2 / 20)$ presented pathological changes in the thoracic region and $15.8 \%(3 / 19)$ presented lesions in the caudal region. None of the 16 animals from which lumbar vertebrae were examined had lesions. Ribs of $17.1 \%(7 / 41)$ of the animals presented pathological changes. In the appendicular skeleton, considering the carcasses that had at least one scapular glenoid fossa and/or head of humerus examined, the scapulohumeral joints of $3.7 \%(1 / 27)$ of the animals presented lesions. In the distal articulation of the humerus, $9.1 \%$ (1/11) of the animals had pathological changes. Radii of $14.3 \%$ (1/7) of the animals presented lesions. No scapular blades $(n=23)$, ulnar articular facets $(n=6)$ or mandibles $(n=8)$ of the animals showed signs of fractures or other lesions.

Table 1. Megaptera novaeangliae. Totals of animals examined by sex and age class and prevalence of pathological changes

\begin{tabular}{|lccc|}
\hline & $\begin{array}{c}\text { No. of animals examined } \\
\text { Total }\end{array}$ & With pathology & \\
\hline Sex & & & \\
Male & 14 & 5 & 35.7 \\
Female & 11 & 1 & 9.1 \\
Undetermined & 24 & 6 & 25.0 \\
Age class & & & \\
Calf & 19 & 0 & 0 \\
Juvenile & 10 & 3 & 40.0 \\
Adult & 13 & 6 & 42.9 \\
Undetermined & 7 & 3 & \\
\hline
\end{tabular}

Table 2. Megaptera novaeangliae. Prevalence of pathological changes in skeletons of humpback whales

\begin{tabular}{|lccc|}
\hline $\begin{array}{l}\text { Skeleton } \\
\text { region }\end{array}$ & $\begin{array}{r}\text { No. of animals examined } \\
\text { Total }\end{array}$ & With pathology & \\
\hline Vertebral column & & & \\
Cervical & 14 & 4 & 28.6 \\
Thoracic & 20 & 2 & 10.0 \\
Lumbar & 16 & 0 & 0 \\
Caudal & 19 & 3 & 15.8 \\
Ribs & 41 & 7 & 17.1 \\
Scapulohumeral joint & 27 & 1 & 3.7 \\
Humerus, distal joint & 11 & 1 & 9.1 \\
Radius & 7 & 1 & 14.3 \\
Ulna & 6 & 0 & 0.0 \\
\hline
\end{tabular}

Degenerative and developmental malformations were observed with higher frequency $(10.2 \% ; 5 / 49)$, followed by inflammatory and traumatic lesions $(8.2 \% ; 4 / 49)$. The description and general data of specimens with lesions are shown in Table 3.

\section{Degenerative diseases}

Spondyloarthrosis resulting from degenerative changes in the intervertebral disk was found in 3 whales. In Specimen 242, erosion and spondylophytes were observed in 2 cervical vertebra and prominent spondylophytes were observed in 2 thoracic and 2 caudal vertebrae. Specimen 238 presented syndesmophyte formation ventrally in the cervical region leading to ankylosis of C2 and C3 (Fig. 1A). Specimen 122 presented degenerative changes on cervical vertebrae $\mathrm{C} 1$ to $\mathrm{C} 4$. Erosion was observed in the caudal epiphyses and spondylophytes in the right lateral margin of $\mathrm{C} 1$ and C2. Ankylosis of C3 and C4 was observed due to syndesmophyte formation in the right lateral of the vertebral body (Fig. 1B). in the same specimen, degenerative changes were also observed in the right scapulohumeral joint, with erosion in the head of the humerus and focally extensive exostosis in the margin of the scapular glenoid fossa.

Arthrotic changes were observed in 13 ribs of Specimen 358. The articular facet of ribs presented variable degrees of erosion and/or cavities and multiple areas of irregular periosteal new bone formation around the neck (Fig. 2A). The third rib on each side presented the most severe lesions with lytic changes and exostosis, leading to deformation of articular facets (Fig. 2B). Unfortunately, vertebrae were not present in the carcass and could not be examined. Specimen 499 presented osteophyte formation in the distal articulation of the humerus. 


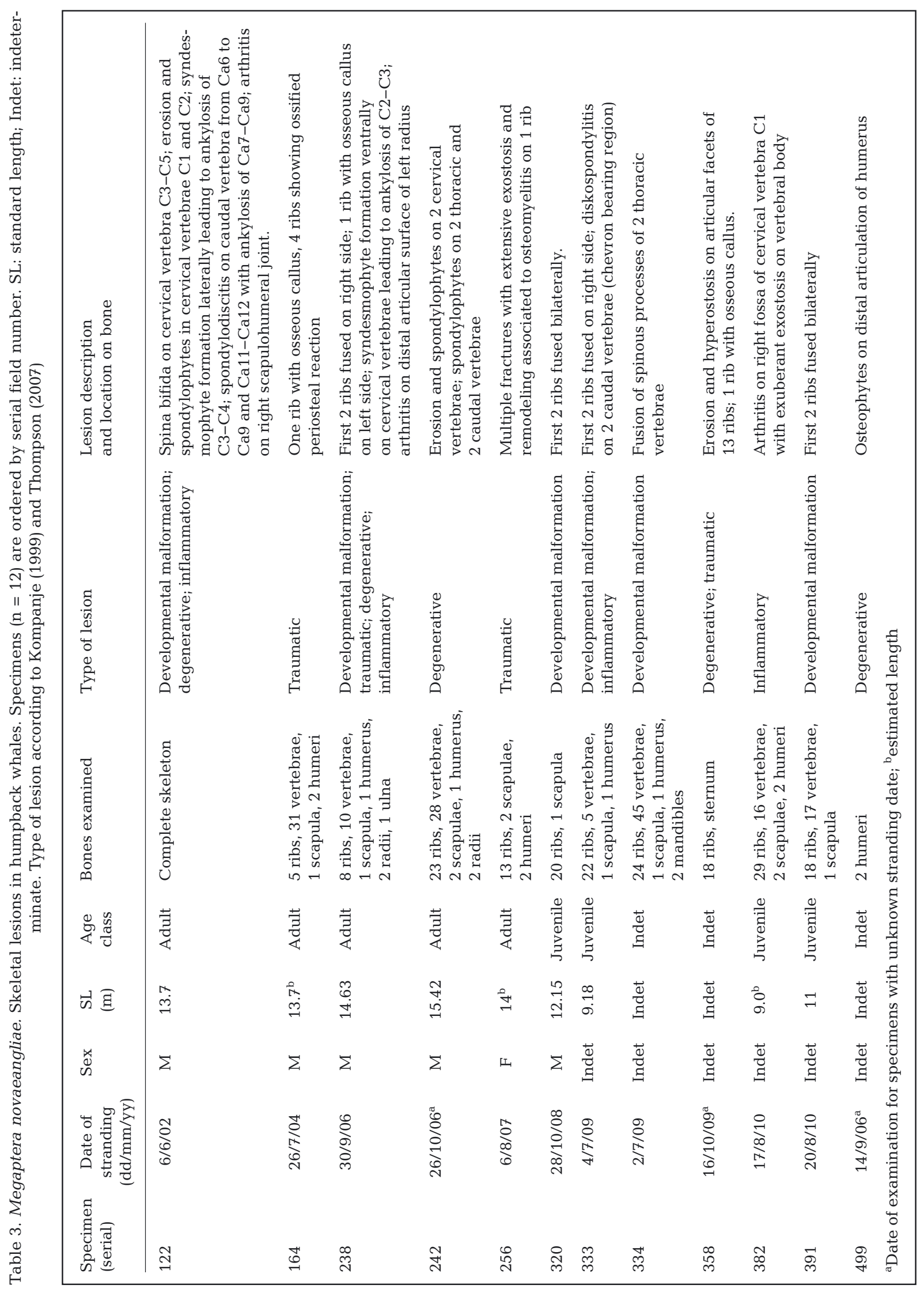



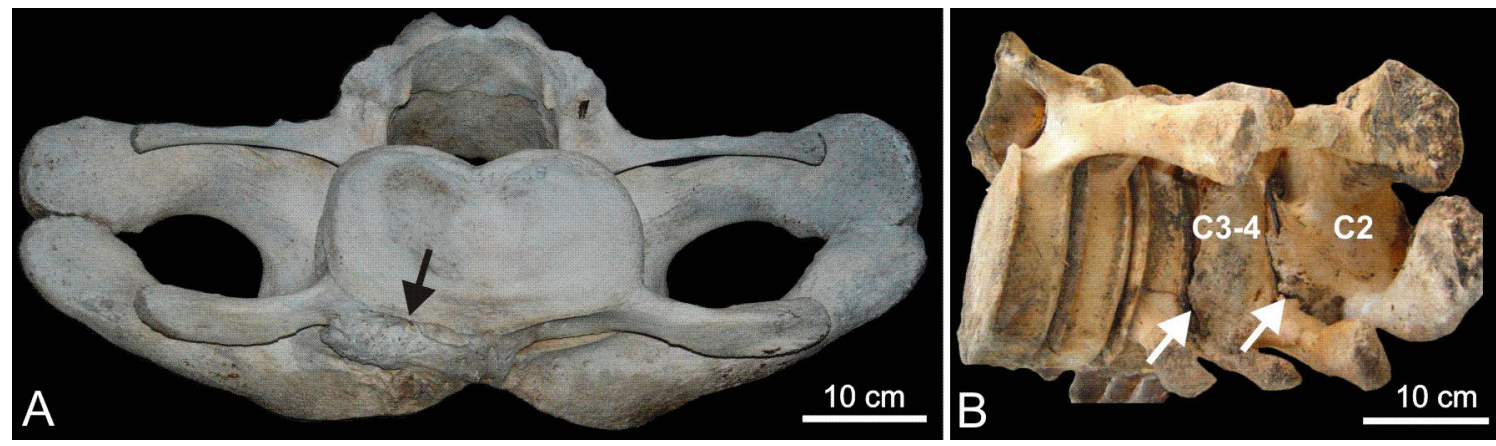

Fig. 1. Megaptera novaeangliae. (A) Specimen 238. Frontal view of cervical vertebrae C2 and C3 with ventral syndesmophyte formation (arrow). (B) Specimen 122. Right lateral view of cervical vertebrae with smooth bony outgrowths resembling bridges between adjacent vertebrae C2 and C4 (arrows), leading to ankylosis of C3 and C4
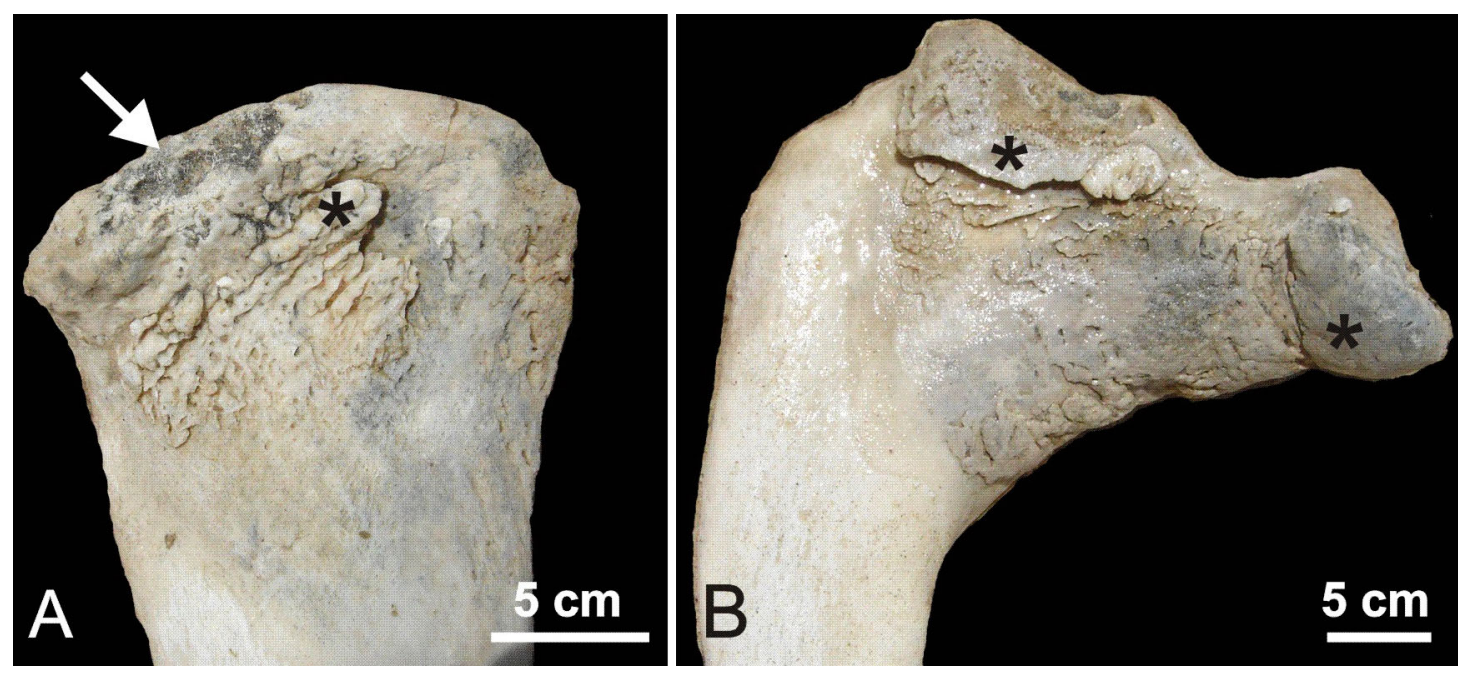

Fig. 2. Megaptera novaeangliae. Specimen 358. Arthrotic changes on articular facets of ribs. (A) Cavities (arrow) and exostosis (asterisk) in one of the ribs. (B) Lateral view of the third left rib showing extensive exostosis (asterisks)

\section{Infectious and inflammatory diseases}

Primary inflammatory diseases were observed in 4 whales. Partial destruction of the distal articular surface of the radius and periosteal proliferative reaction was observed in Specimen 238 (Fig. 3A). In the vertebral column, Specimen 382 presented extensive erosion of the right fossa of the atlantooccipital joint, with extensive irregular exostosis along the whole right lateral aspect of the vertebral body (Fig. 3B). In one juvenile whale (Specimen 333), 2 caudal vertebrae had extensive erosion and cavities on adjoining end plates and exuberant irregular bony proliferation on the entire circumferences of their vertebral bodies, but the neural canal did not appear to be compromised (Fig. 4). The animal was found stranded with an abnormally high incidence of whale lice (Cyamus sp.) covering more than $60 \%$ of the skin. No evidence of infection or a specific cause of death was found during partial necropsy. Lesions in the skeletal system were found $1 \mathrm{wk}$ later, when the team returned to the stranding site to examine bones that had not been carried away by the tide. At that time, there were only 5 vertebrae remaining, the last 2 being those affected.

Specimen 122 presented exuberant irregular exostosis around the body of 6 caudal vertebrae, Ca6 to Ca9 and Ca11 to Ca12, clearly more developed on the left side. Vertebrae Ca7 to Ca9 and at least one chevron bone were almost completely ankylosed (Fig. 5). Severe disk impairment is evident due to diminished intervertebral space between these vertebrae. Severe erosion and cavities on the caudal epiphysis of Ca6 and Ca11 and on the cranial epiphysis of $\mathrm{Ca} 7$ and $\mathrm{Ca} 12$ were observed, with complete destruction of the cranial end plate 

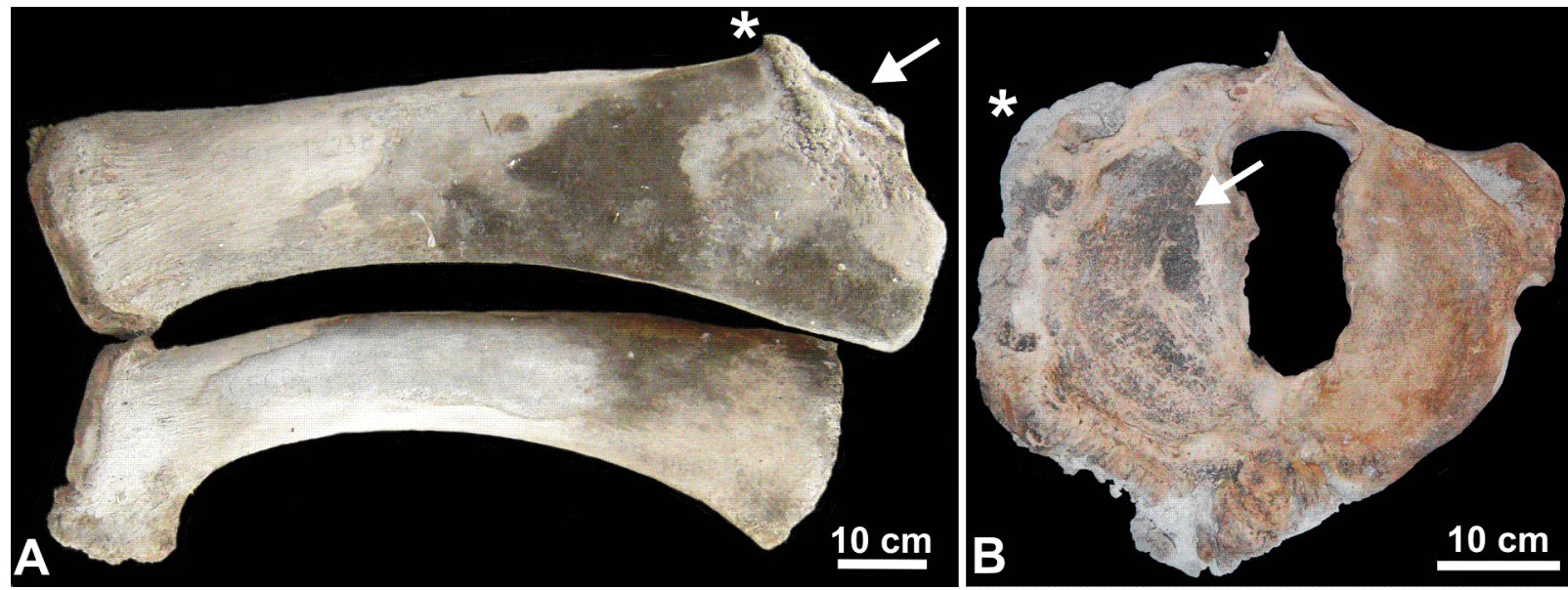

Fig. 3. Megaptera novaeangliae. (A) Specimen 238, radius and ulna. Arthritis on the distal articular surface of radius showing its partial destruction (arrow) and proliferative reaction on the margins of the lesion (asterisk). (B) Specimen 382, atlas. Extensive erosion of the right glenoid fossa of atlas (arrow) and irregular exostosis on the whole right lateral of the vertebral body (asterisk)

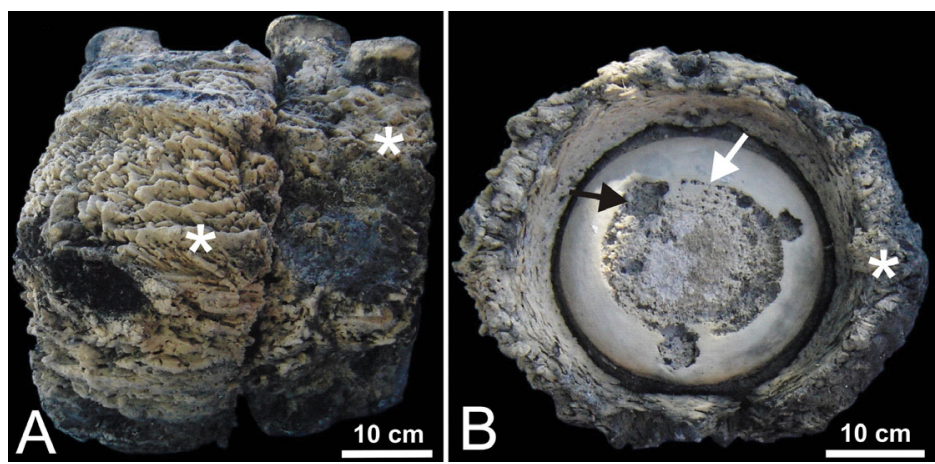

Fig. 4. Megaptera novaeangliae. Specimen 333. (A) Lateral view of 2 caudal vertebrae with irregular bony proliferation (asterisks). (B) Vertebral epiphysis of the left vertebrae shown in (A) presenting severe erosion, cavities (black arrow) and eburnation (white arrow). Note the thick layer of exuberant exostosis over the whole circumference of the vertebral body (asterisk)

of Ca12. This finding indicates that there was a disruption of the intervertebral disks between Ca6 and Ca7, and between Ca11 and Ca12. It seems that 2 separate processes have taken place in the animal, interspersed by an unaffected vertebra (Ca10).

\section{Developmental malformations}

Fusion of the distal portion of spinal processes of 2 thoracic vertebrae was found in one specimen (334). Spina bifida, a developmental anomaly in which the neural arch fails to fuse in the midline, leaving an opening dorsally in the medullar canal, was found in Specimen 122 on cervical vertebrae C3 to C5 (Fig. 6).

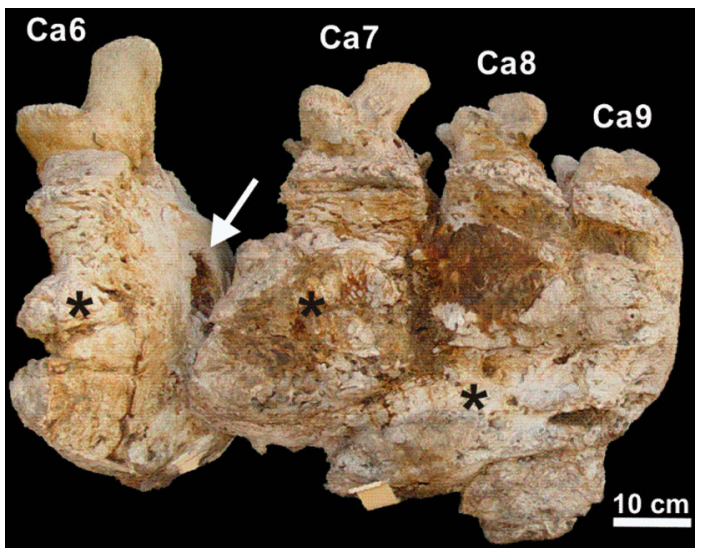

Fig. 5. Megaptera novaeangliae. Specimen 122. Lateral view of the caudal vertebrae showing severe erosion and cavities on distal epiphysis of Ca6 (arrow) and exuberant irregular exostosis (asterisks) leading to ankylosis of $\mathrm{Ca} 7$ to $\mathrm{Ca} 9$ and the chevron bone

Fusion of the ipsilateral first 2 ribs was found in 4 whales. The fusion was bilateral in 2 specimens and unilateral in the other 2 specimens. The fusion pattern differed between individuals as well as in the same individual. Specimen 320 had bilateral rib fusion forming bicipital ribs, where most of the length of the rib was fused into one mass, forming an enlarged plate distally with 2 well-differentiated heads proximally, which articulate with the respective transverse processes. In Specimen 391, the mid to proximal region of the right first and second ribs was fused, leaving distinct distal regions. Proximally, a small underdeveloped head of the first rib was partially fused to a well-developed 


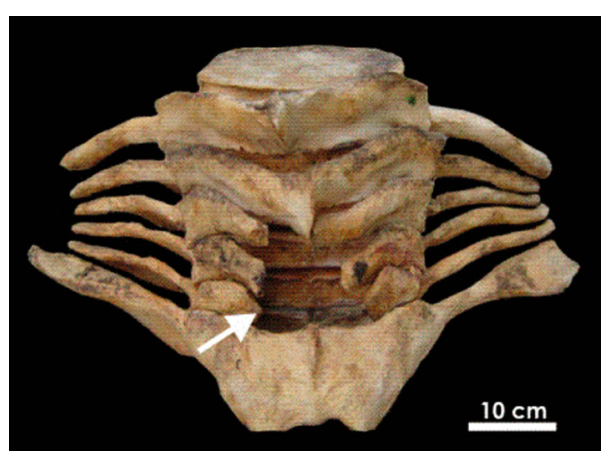

Fig. 6. Megaptera novaeangliae. Specimen 122. Dorsal view of the cervical vertebrae $\mathrm{C} 2$ to $\mathrm{C} 7$ showing open neural channel on C3 to C5 (arrow)

head of the second rib, which seems to be articulated with the transverse processes of the juxtaposed thoracic vertebra. The contralateral first 2 ribs were almost completely fused, forming a wide plate distally and 2 heads proximally, one well differentiated and another underdeveloped (Fig. 7). Of whales that had unilateral rib fusion, Specimen 333 presented with fusion in the mid to proximal region with well-differentiated distal portions of the ribs, one well-developed head and another head poorly differentiated. Specimen 238 presented unilateral rib fusion with a distinct bicipital proximal region.

\section{Traumatic lesions}

Well-consolidated fractures were observed in the ribs of 3 whales. Specimen 164 presented a clear osseous callus on one rib and an ossified periosteal reaction on 4 additional ribs. Specimens 238 and 358 had evident osseous callus on one rib. The skin and subcutaneous tissue overlying the fracture site was evaluated only in specimen 238 and did not show open wounds or scars. Specimen 256 presented extensive exostosis and remodeling, covering approximately two-thirds of the mid portion of the rib, almost doubling its expected diameter compared with the normal appearance of the extremities (Fig. 8). The rib presented with an accentuated curvature and a misalignment compared with other examined ribs. No lesions were observed in the other 12 ribs exam-

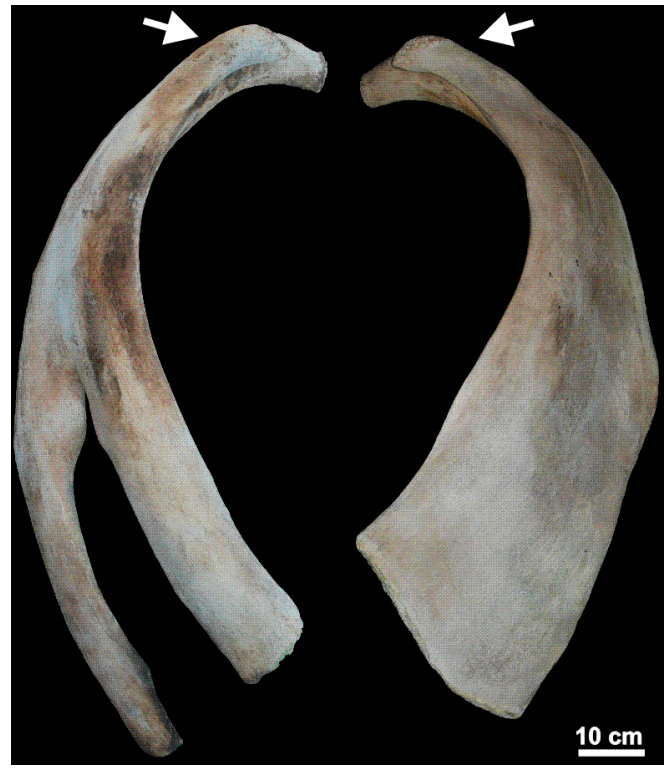

Fig. 7. Megaptera novaeangliae. Specimen 391. Bilateral fusion of the first 2 ribs showing different patterns distally and 2 heads proximally, one well differentiated and the other underdeveloped (arrows)

ined from this animal. The carcass was buried and the other bones could not be accessed. Radiographs and CT scans illustrated a chronic osteomyelitis associated with periosteal proliferation and subperiosteal new bone formation. In most areas, destruction of the normal rib architecture was observed, and the periosteal new bone invaded the medullary cavity. In cross-sections, 3 regions with linear radiolucency over most of the full rib thickness were observed and indicate regions of fractures. In one of these regions, the prominent exostosis resembled an osseous callus (Fig. 9A). The radiolucent areas form cavities and fistulae lined by material with higher density (Fig. 9B,C).

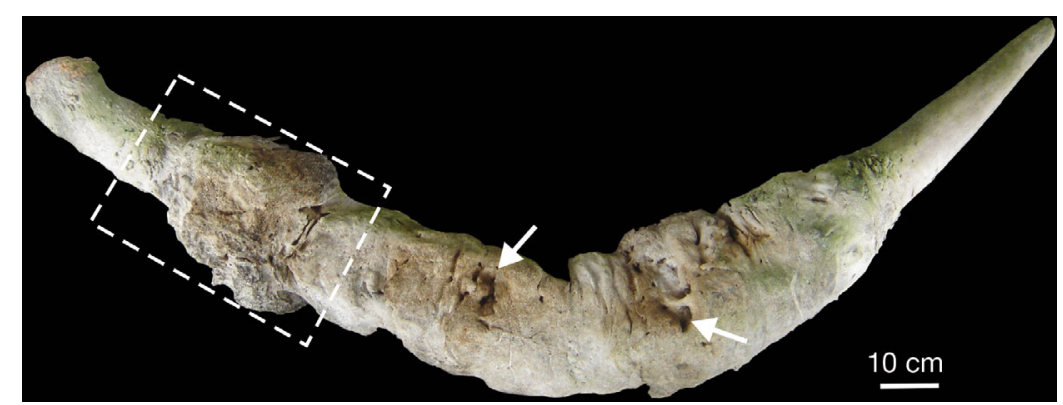

Fig. 8. Megaptera novaeangliae. Specimen 256. Extensive bony growth and remodeling of one rib. Note the presence of osseous callus (dashed rectangle) and multifocal cavities (arrows). Normal appearance of the rib is observed in both extremities 


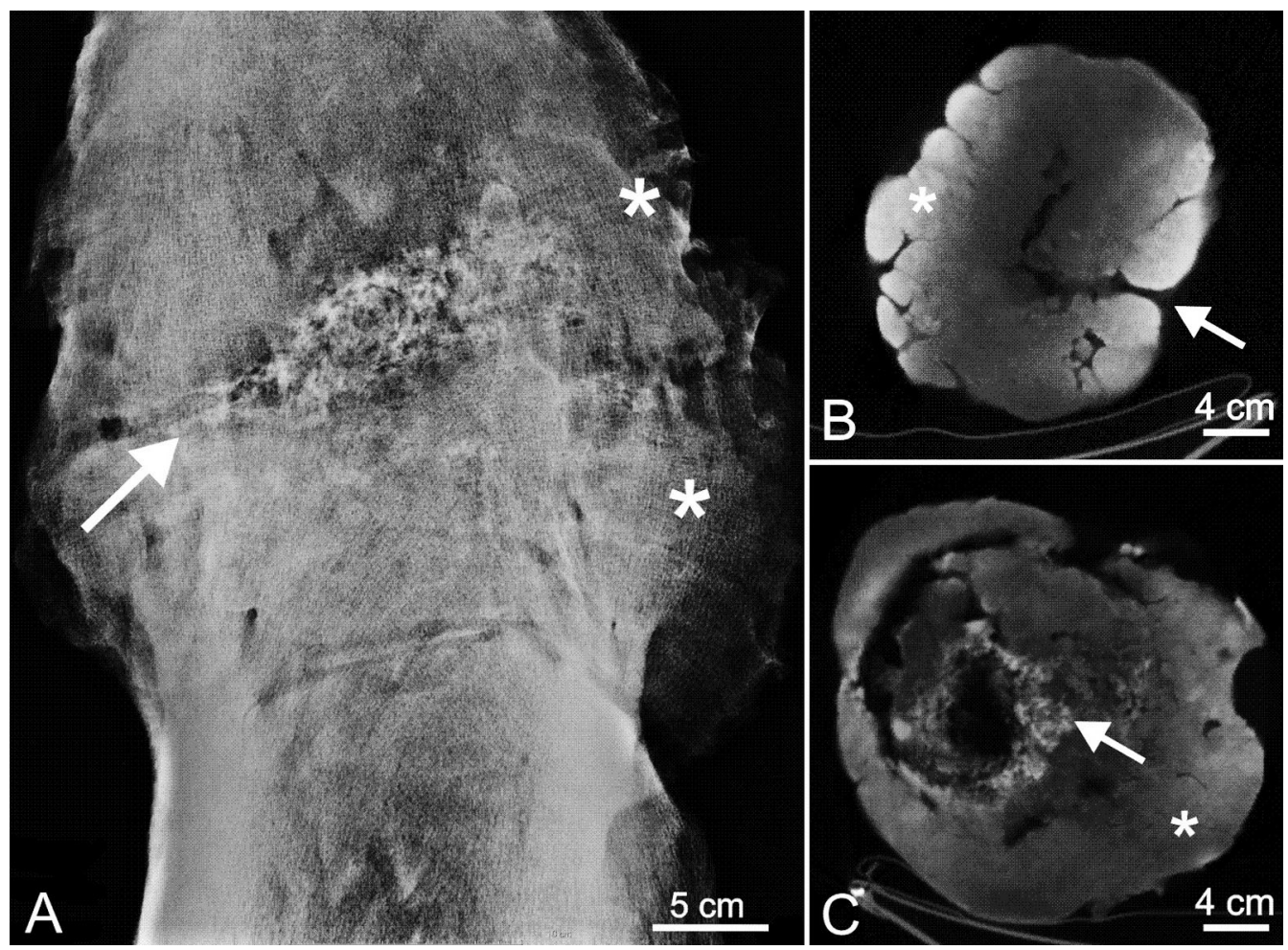

Fig. 9. Megaptera novaeangliae. Specimen 256. (A) Radiograph of the rib region marked by the dashed rectangle in Fig. 8. Note the linear radiolucent area (arrow) surrounded by large osseous callus (asterisks). (B,C) Computed tomographs of the rib. Note periosteal exostosis (asterisks), fistulae ( $\mathrm{B}$, arrow) and cavities lined with material with higher density $(\mathrm{C}$, arrow)

\section{DISCUSSION}

After the protection of humpback whales in Brazil (Brazil Federal Decree no. 211, 28 Feb 1962) and the statutory ban of commercial whaling at the end of the last century (Brazil Federal Law no. 7.643, 18 Dec 1987), the population of humpback whales has shown evidence of recovery (Andriolo et al. 2010). Despite increases in the population, little is known about the health conditions, threats and impacts on this species, and how these factors may affect its recovery.

However, assessing the health of large whales in the wild is a difficult task. Stranded humpback whales are often found dead, in states of advanced decomposition, with only skeletal remains available for diagnostic examination. The gross evaluation of bone may contribute to the understanding of pathologic processes that affect the health of these animals. In fact, like other systems, the skeletal system reacts to injury and is susceptible to circulatory, inflammatory, neoplastic, metabolic and developmental disorders (Rosenberg 2005). Evidence of infectious and degenerative diseases for example, has been inferred through osseous changes in cetaceans (Cowan 1966, De Smet 1977, Morton 1978, Kinze 1986, Kompanje 1995a, 1999, Sweeny et al. 2005, Félix et al. 2007, Simões-Lopes et al. 2008).

Skeletal abnormalities have been documented in several species of cetaceans; however, published information on osseous pathology in humpback whales is scarce. Five single cases have been reported (Stede 1994, Paterson \& Van Dyck 1996, Kompanje 1999, Félix et al. 2007, Hellier et al. 2011). Analysis usually relies on museum specimens, or stranded animals dissected with the purpose of collecting the skeleton. To our knowledge, this is the first report on bone pathology of humpback whales from the southwestern Atlantic Ocean and the first study on skeletal abnormalities based on the systematic analysis of skeletal remains of stranded whales.

Skeletal changes were found in at least $24.5 \%$ $(12 / 49)$ of the humpback whales examined. A higher percentage was found in males than in females. However, it is important to consider that in most cases, the sex was not determined (due to absent distinctive features or tissue sample suitable for genetic analysis) and a prolapsed penis in decomposed car- 
casses facilitates identifying males. In this case series, calves stranded with higher frequency; however, skeletal lesions were observed only in juveniles and adult animals. A higher incidence of stranded calves is expected, since the region is used for calving. The low incidence of skeletal abnormalities in calves may be explained because of the grossly recognizable bony changes that may take some time to be established and may not be readily identified in the first months after birth. However, traumatic injuries to bones from the infanticide behavior of adult dolphins have been documented in bottlenose dolphin Tursiops truncatus calves (Patterson et al. 1998, Dunn et al. 2002). Injuries consistent with compression during parturition have been reported in a humpback whale and a minke whale Balaenoptera acutorostrata (Paterson \& Van Dyck 1996). Furthermore, a condition described as osteoperiostitis ossificans hypertrophicans was recognized in the caudal vertebra of a $6.9 \mathrm{~m}$ female humpback whale calf from Germany (Stede 1994), demonstrating that skeletal changes may be recognized in any stage of life.

The skeletal survey of large whales is quite challenging due to difficulties related to the animal's size, necessary logistics and limitations imposed by tidal variations. These limitations unfortunately precluded reliable skull examination in most cases in the present study; however, skulls of 4 animals presented with scavenging or post mortem damage. The number of bones examined per animal varied from 2 to the entire postcranial skeleton. These results are therefore conservative estimates of the prevalence of lesions as it was not possible to address the condition of all bones in the majority of the carcasses.

In the vertebral column, inflammatory conditions were found in the cervical region of one whale involving the atlantooccipital joint (Specimen 382) and in the caudal region of 2 other whales, involving 2 vertebrae of a juvenile whale (Specimen 333) and 6 vertebrae of an adult whale (Specimen 122), on which the lesions led to ankylosis of 3 vertebrae and at least 1 chevron bone. In the case of Specimen 382 (Fig. 3B), the lesion observed in the atlas with severe extensive articular surface destruction and exuberant irregular bone reaction suggests an inflammatory etiology, considering that in degenerative conditions the exostosis would generally be more regular, well defined and smooth. Pathological changes in the atlantooccipital joint have been diagnosed as degenerative joint disease in 3 bottlenose dolphins, one pantropical spotted dolphin Stenella attenuata and one pygmy sperm whale Kogia breviceps, while infectious inflammatory arthritis was reported in 3 specimens of bottlenose dolphin from the western coast of the Gulf of Mexico (Turnbull \& Cowan 1999). The deformations observed in the caudal vertebrae of Specimens 333 and 122 (Figs. 4 \& 5, respectively) are presumably due to a chronic bacterial infection affecting intervertebral disks and adjacent vertebral bodies (spondylodiscitis or infectious spondylitis). Differential diagnosis includes spondyloarthritis, a group of inflammatory diseases related to genetic and environmental factors (including ankylosing spondylitis, Reiter's syndrome, and reactive arthritis, among others), known to occur in humans predominantly with positive Human Leukocyte Antigen b27 (François et al. 1995). This process was suspected to occur in fin whales Balaenoptera physalus and in one humpback whale from Denmark (Kompanje 1999), as well as in one humpback whale from Ecuador (Félix et al. 2007). Spondyloarthritis is grossly characterized by ossification of perivertebral ligaments and connective tissues outside the annulus fibrous forming bony bridging between consecutive vertebral bodies without evidence of intervertebral disk degeneration, as well as by the presence of paradiscal ossicles and changes of zygapophyseal joints (Kompanje 1999). In Specimens 122 and 333, injury of the intervertebral disk was evident and diagnosis of spondylodiscitis seems to be appropriate. Kompanje (1999) reported similar lesions in the bowhead whale Balaena mysticetus, the blue whale Balaenoptera musculus and Bryde's whale Balaenoptera edeni. In odontocete cetaceans, lesions with the characteristics of spondylodiscitis have been reported in the long-finned pilot whale Globicephala melas (Cowan 1966), the bottlenose dolphin (Morton 1978, Alexander et al. 1989, Kompanje 1999), the Guiana dolphin Sotalia guianensis (Simões-Lopes et al. 2008), Sowerby's beaked whale Mesoplodon bidens, the harbor porpoise Phocoena phocoena (Kompanje 1995b, 1999), the white-beaked dolphin Lagenorhynchus albirostris, the Atlantic white-sided dolphin Lagenorhynchus acutus, the short-beaked common dolphin Delphinus delphis, the false killer whale Pseudorca crassidens, the killer whale Orcinus orca and the Irrawaddy dolphin Orcaella brevirostris (Kompanje 1999).

Infectious agents are capable of compromising joints in humans and domestic animals. Arthritis may also be a manifestation of systemic infection. Certain infectious agents may initiate an immune-mediated reaction to nonviable bacterial components in response to infection at sites distant from the joint (Thompson 2007). In the juvenile specimen (Specimen 333), a male of $9.18 \mathrm{~m}$ body length, external 
examination did not show evidence of injury or a penetrating wound that could cause the direct implantation of infectious agents from the skin surface into the joint. Hematogenous infection of vertebrae is common in domestic animals as a sequel to neonatal bacteremia or septicemia following omphalophlebitis or infections of the gastrointestinal tract or lungs (Thompson 2007). Inadequate transfer of colostrum immunoglobulins is a predisposing factor. In this case, it is possible that the lesion occurred secondarily to an infection elsewhere in the body. Unfortunately, necropsy was not performed on the adult specimen (Specimen 122); however, in adult domestic animals, infection of joints is often induced by external and internal traumatic events.

Externally, Specimen 333 also showed a relatively high infestation of whale lice. An adult humpback whale with marked scoliosis in the caudal region was found almost motionless and heavily parasitized by whale lice off the coast of Maui (Osmond \& Kaufman 1998). The young humpback whale with lesions on lumbar and caudal vertebrae reported by Félix et al. (2007) also showed an abnormally high cyamid infestation. Cyamids are epibionts specialized in feeding on whale skin, normally found in low quantities over the skin of whales. The infestation level is possibly controlled by the removal rates during swimming and surfacing behaviors (i.e. breaching and tail slapping). An abnormally high infestation is usually associated with debilitated animals and may be a consequence of decreased mobility (Pfeiffer 2009). Like other cetaceans, the movement of whales is produced through the up-and-down movement of the peduncle and propulsion of the fluke (Slijper 1946). As suggested by Osmond \& Kaufman (1998) and Félix et al. (2007), the infestation may be a consequence of severe lesions in the vertebral column. Therefore, it is possible that the lesions found in the axial skeleton of Specimen 333 may have reduced its mobility and fitness, leading to an increase in ectoparasites. Since the maneuverability and the tail are also the major defenses against predators such as sharks and killer whales (Chittleborough 1953), lesions compromising mobility may predispose the animal to predation. Furthermore, chronic inflammatory lesions may be detrimental to the general health of these animals. For these reasons, we believe that the lesions found in the caudal vertebrae of Specimens 122 and 333 may have contributed to their stranding and death.

Three animals showed lesions in the flipper. Degenerative changes were found in the scapulohumeral joint of Specimen 122 and in the distal articulation of humerus of Specimen 499. Severe arthritic changes were observed in the radius of Specimen 238 (Fig. 3A). A similar inflammatory lesion on the right radius with bony lysis and periosteal reaction was reported in a North Atlantic right whale Eubalaena glacialis associated with entangled fishing gear (Moore et al. 2004). In the present case, there was no external evidence of entanglement; however, the pectoral fin was found completely sectioned at the lesion level with distal structures missing, and the entanglement hypothesis cannot be ruled out. Differential diagnosis includes penetrating and blunt trauma from unknown origin and infection of adjacent tissues.

Spondyloarthrosis was found in the cervical region of 3 whales (Specimens 242, 238 and 122; Fig. 1) and also in the thoracic and caudal regions of 1 whale (Specimen 242). Primary degenerative joint disease occurs in older animals without any apparent predisposing cause. Secondary degenerative joint disease is caused by direct damage, poor conformation, and instability or abnormal directional forces in the joint or supporting structures, predisposing the animal to degenerative changes, and can occur in adult and in immature animals (Thompson 2007). Differential diagnosis includes spondylodiscitis and spondyloarthritis (Kompanje 1999, Thompson 2007). Alhough it was not possible to verify the condition of congruent endplates of ankylosed cervical vertebrae, erosion was present in non-ankylosed vertebrae, paradiscal ossicles were not observed and zygapophyseal joints were normal. The diagnosis of intervertebral disk degeneration leading to spondyloarthrosis was judged more appropriate in these cases. The condition is also known as discarthrosis, spondylosis deformans or spondylitis deformans. Similar lesions have been reported in the Guiana dolphin (Furtado \& Simões-Lopes 1999, Simões-Lopes et al. 2008), the white-beaked dolphin (Van Bree \& Nijssen 1964, Kompanje 1995a, Galatius et al. 2009), the harbor porpoise (Kinze 1986), the bottlenose dolphin (Furtado \& Simões-Lopes 1999, Kompanje 1999), the false killer whale, the short-finned pilot whale Globicephala macrorhynchus, the beluga Delphinapterus leucas, the northern bottlenose whale Hyperoodon ampullatus, Hector's beaked whale Mesoplodon hectori and True's beaked whale Mesoplodon mirus (Kompanje 1999), and the rough-toothed dolphin Steno bredanensis, the Atlantic spotted dolphin Stenella frontalis, the clymene dolphin Stenella clymene and the long-beaked common dolphin Delphinus capensis (Furtado \& Simões-Lopes 1999).

Bilateral, erosive and remodeling lesions on subchondral rib surfaces were observed in 13 ribs of 
Specimen 358 (Fig. 2). Similar lesions have been reported in sperm whales Physeter macrocephalus and were diagnosed as osteonecrosis, possibly resulting from dysbaric stress (Moore \& Early 2004). Differential diagnosis to this process includes infection and autoimmune inflammatory reaction. At present, there is no evidence that humpback whales can undergo lesions associated with dysbaric stress and complementary studies would be necessary to clarify this hypothesis. In the present case, the pathological changes observed on ribs are likely of degenerative etiology.

The presence of osseous callus was observed in the ribs of 3 whales (Specimens 164, 238 and 358), with evidence of fracture or fissure repair. Fractures in large whales have been reported in ribs of an $18.9 \mathrm{~m}$ fin whale (Hellier et al. 2011), in the mandible of a $11.4 \mathrm{~m}$ bowhead whale (Philo et al. 1990) and in the radius and ulna of a skeletally immature fin whale (Ogden et al. 1981) of unknown origin. Bilaterally fractured ribs and superficial focally extensive cystic osseous lesions associated with periosteal new bone formation dorsolaterally in the supra-orbital region were observed in a humpback whale and a minke whale calf from Australia; these lesions were consistent with trauma during parturition (Paterson \& Van Dyck 1996). Fractures on the mandible, skull and thoracic transverse process of North Atlantic right whales were attributed to propeller cuts or massive blunt trauma from ship collision (Moore et al. 2004). In odontocete cetaceans, rib fractures are apparently common (Cowan 1966, De Smet 1977, Kompanje 1995c, Dunn et al. 2002, Simões-Lopes et al. 2008). In our cases, the causes of fractures were not apparent. The fracture may be pathological or a result of blunt trauma. A pathological fracture could have been the result of neoplasia, osteomyelitis or degenerative bone disease. Blunt trauma could have occurred from ship collision, a result of aggressive intraspecific or interspecific behavior, or interaction with predators (De Smet 1977, Philo et al. 1990, Ross \& Wilson 1996, Patterson et al. 1998, Dunn et al. 2002, Moore et al. 2004). In cases found with a well-formed osseous callous, there was no macroscopic evidence to support the diagnosis of pathological fracture and a traumatic event was considered to be more likely. However, histological and radiological studies would be necessary to confirm this hypothesis.

Specimen 256 (Fig. 8) presented extensive bony growth and remodeling that covered approximately two-thirds of the rib, yet both extremities were relatively normal. The rib showed accentuated curvature and a misalignment. Radiological images evidenced multiple sites of possible fractures (Fig. 9). Our hypothesis is that one or more fractures triggered the infection leading to osteomyelitis; however, it is uncertain whether osteomyelitis was already present, predisposing the bone to pathological fractures. The formation of the osseous callus was chronically stimulated, leading to extensive diffuse exostosis and osseous remodeling. The overall radiological appearance was similar to the infectious form of a condition known in humans as diffuse sclerosing osteomyelitis (DSO), with extensive sclerosis and periosteal new bone formation associated with infection (Groot et al 1996). In this case, it is possible that the secondary infection of multiple complicated fractures in the rib induced a chronic reparative reaction, producing features similar to those of DSO. Lesions with grossly similar appearance, attributed to several healed fractures with complicating osteomyelitis, were found in one rib of killer whale found in Wieringen Island, Holland (Kompanje 1991).

Fusion of the first 2 cranial ribs was found in 4 whales, both unilaterally (Specimens 333 and 238) and bilaterally (Specimens 320 and 391; Fig. 7). A similar condition has been mentioned in literature as a bicipital, bifid or double-headed rib (Turner 1871, Allen 1916, Nishiwaki \& Kasuya 1971, Omura et al. 1981, DeLynn et al. 2011). This developmental abnormality is characterized as the fusion of the first 2 ribs with a cleft in the vertebral end, originating 2 distinct processes that may articulate with the last cervical and first thoracic vertebra or with the first 2 thoracic vertebrae, which has occasionally been observed in large whale skeleton museum specimens, including species such as the North Atlantic right whale (Allen 1916), the southern right whale Eubalaena australis, the blue whale (Turner 1871), the sei whale Balaenoptera borealis (Slijper 1936, Nishiwaki \& Kasuya 1971) and Bryde's whale (Slijper 1936, Omura et al. 1981). In the present study, bicipital ribs were found unilaterally and bilaterally in humpback whales. Additionally, another form of abnormality with fusion of ribs forming 1 or 2 distinct processes in the vertebral end and 2 processes in the sternal end has been found. To our knowledge, this form of fusion has only been described bilaterally in a blue whale by Slijper (1936). Unilaterally fused fifth and sixth ribs with distinct extremities, associated with a deformed sternum and rib cage distortion, have been reported in the bottlenose dolphin (DeLynn et al. 2011). The specimen also presented with bilateral bicipital ribs and severe developmental malformations in the axial skeleton (DeLynn et al. 2011). In the present study, 
this condition was found unilaterally and bilaterally in specimens with either normal or bicipital rib fusion of the first 2 ribs in the contralateral side.

Spina bifida was observed in 3 cervical vertebrae of Specimen 122 (Fig. 6). Spina bifida results from defective closure of dorsal vertebral laminae in a vertebral column segment (Thompson 2007). Two categories of spina bifida malformations may be considered in the present case: spina bifida occulta, without protrusion of the spinal cord or meninges, and spina bifida cystic, in which there is protrusion through the defective vertebral arch of a cystic swelling, involving the meninges, spinal cord or both (Dorland 1997). Defective arch closure was reported in the longfinned pilot whale, mostly involving thoracic vertebrae (Cowan 1966). In domestic animals, it has been reported in canine, feline, bovine, equine and ovine specimens (Wilson et al. 1979, LeCouteur \& Grandy 2010) and may be associated with various soft tissue defects including defective innervations of muscle groups, kidney fusion and uterine aplasia (Thompson 2007). Degenerative changes were observed in the spinal column of an 18-yr-old bottlenose dolphin with multiple developmental abnormalities in the axial skeleton (DeLynn et al. 2011). In the present case, the cervical vertebra showing spina bifida also had spondyloarthrosis, leading to ankylosis. It is unclear whether the lesions are associated, but it should be considered. Overall, because it was an adult animal, the condition may not have caused major disabilities which would compromise its survival and may have manifested as the occult form (spina bifida occulta).

The developmental malformations documented herein are apparently incidental findings of no major concern to the health of these individuals; however, it is unknown whether they were associated with abnormalities in adjacent soft tissues and organs. Therefore, further studies should be carried out to elucidate whether skeletal abnormalities affect innervations, vasculature pathways and tendon insertions or predispose animals to degenerative changes.

This study contributes to a better understanding of the skeletal disorders in humpback whales, adding new information from 12 cases out of 49 animals, which shows that approximately one-quarter of the animals had at least one type of lesion. This is a conservative estimate in view of the limitations on the number of bones examined per animal. Therefore, efforts to examine skeletal tissues during necropsy are encouraged and provide additional insights into the life history and morbid conditions of the animals found in advanced stage of decomposition. Complementary diagnostic techniques are needed to better understand and differentiate pathologic conditions affecting bones. Diagnostic imaging techniques are valuable tools (Sweeny et al. 2005). Bacteriology and molecular techniques are needed for the survey of possible etiologic agents involved on infectious conditions. Histopathological and immunohistochemical analyses of bone and adjacent soft tissue may provide further understanding on the etiology and pathogenesis of these conditions.

Acknowledgements. We thank Sr. Ariosvaldo Pinto dos Santos and volunteers for the invaluable support in the fieldwork; Projeto TAMAR, Parque Estadual de Itaúnas and Instituto Orca for the logistical support in many stranding events; Prof. Dr. Paulo César Simões-Lopes for providing many papers for the review of literature; Prof. Dr. Sentiel Rommel, Dr. Erwin J. O. Kompanje and 2 anonymous referees for very helpful comments on the manuscript; and Prof. Dr. Rainer Haetinger and Dr. Enio César Vieira Pereira for help with the interpretation of radiographic images. The support of Fundação de Amparo à Pesquisa do Estado de São Paulo (FAPESP), processes 2010/50094-3, 2011/08357-0 and 2012/00021-5, is greatly appreciated. Veracel Celulose provided financial support to the Rescue Program. Projeto Baleia Jubarte is sponsored by Petroleo Brasileiro (Petrobras). J.L.C.D. is a recipient of a professorship by the Conselho Nacional de Desenvolvimento Científico e TecnológicoCNPq (301517/2006-1). This study was conducted by K.R.G. as partial fulfillment of the requirements for the doctoral degree at the Departamento de Patologia, Faculdade de Medicina Veterinária e Zootecnia, Universidade de São Paulo.

\section{LITERATURE CITED}

Alexander JW, Solangi MA, Riegel LS (1989) Vertebral osteomyelitis and suspected diskospondylitis in an Atlantic bottlenose dolphin (Tursiops truncatus). J Wildl Dis 25:118-121

Allen GM (1916) The whalebone whales of New England. Mem Boston Soc Nat Hist 8:105-322

Andriolo A, Martins CCA, Engel MH, Pizzorno JL, and others (2006) The first aerial survey to estimate abundance of humpback whales (Megaptera novaeangliae) in the breeding ground off Brazil (breeding stock A). J Cetacean Res Manag 8:307-311

Andriolo A, Kinas PG, Engel MH, Albuquerque Martins CC, Rufino AM (2010) Humpback whales within the Brazilian breeding ground: distribution and population size estimate. Endang Species Res 11:233-243

> Chittleborough RG (1953) Aerial observations on the humpback whale, Megaptera nodosa (Bonaterre), with notes on other species. Aust J Mar Freshw Res 4:219-226

$>$ Cowan DF (1966) Pathology of the pilot whale. Globicephala melaena. A comparative survey. Arch Pathol 82:178-189

> Cypriano-Souza AL, Fernández GP, Lima-Rosa CA, Engel MH, Bonatto SL (2009) Microsatellite genetic characterization of the humpback whale (Megaptera novaeangliae) breeding ground off Brazil (breeding stock A). J Hered 101:189-200 
De Smet WMA (1977) The fate of old bottle-nosed dolphins, Tursiops truncatus, in nature as revealed by the condition of their skeletons. Aquat Mamm 5:48-86

> DeLynn R, Lovewell G, Wells RS, Early G (2011) Congenital scoliosis of a bottlenose dolphin. J Wildl Dis 47:979-983

Dorland WAN (1997) Dorland's illustrated medical dictionary. Saunders, Philadelphia, PA

> Dunn DG, Barco SG, Pabst DA, McLellan WA (2002) Evidence for infanticide in bottlenose dolphins of the western north Atlantic. J Wildl Dis 38:505-510

Engel MH, Fagundes NJR, Rosenbaum HC, Ott $\mathrm{PH}$, and others (2006) Mitochondrial DNA variability and evaluation of the likely feeding grounds of the humpback whale (Megaptera novaeangliae) population of the Abrolhos bank, Bahia, Brazil. International Whaling Commission, Hobart

Félix F, Haase B, Aguirre WE (2007) Spondylitis in a humpback whale (Megaptera novaeangliae) from the southeast Pacific. Dis Aquat Org 75:259-264

François RJ, Eulderink F, Bywaters EG (1995) Commented glossary for rheumatic spinal diseases, based on pathology. Ann Rheum Dis 54:615-625

Furtado MHBC, Simões-Lopes PC (1999) Alterações senildegenerativas e variações anatômicas na coluna vertebral de pequenos cetáceos. Biotemas 12:133-147 (with English abstract)

Galatius A, Sonne C, Kinze CC, Dietz R, Jensen JEB (2009) Occurrence of vertebral osteophytosis in a museum sample of white-beaked dolphins (Lagenorhynchus albirostris) from Danish waters. J Wildl Dis 45:19-28

Groot RH, van Merkesteyn JP, Bras J (1996) Diffuse sclerosing osteomyelitis and florid osseus dysplasia. Oral Surg Oral Med Oral Pathol Oral Radiol Endod 81:333-342

Hellier CA, Hufthammer AK, Lislevand T (2011) Osteological pathology in a humpback (Megaptera novaeangliae) and fin (Balaenoptera physalus) whale skeleton. Int J Paleopathol 1:117-120

Kinze CC (1986) Note on the orcurrence of Spondylitis deformans in a sample of harbor porpoises (Phocoena phocoena) taken in Danish waters. Aquat Mamm 12: 25-27

Kompanje EJO (1991) Een oud geval van osteomyelitis bij een orka Orcinus orca [An old case of osteomyelitis in a killer whale Orcinus orca]. Lutra 34:71-76 (with English abstract)

Kompanje EJO (1995a) On the occurrence of spondylosis deformans in white-beaked dolphins Lagenorhynchus albirostris (Gray, 1846) stranded on the Dutch coast. Zool Med Leiden 69:231-250

Kompanje EJO (1995b) Differences between spondyloosteomyelitis and spondylosis deformans in small odontocetes based on museum material. Aquat Mamm 21: 199-203

Kompanje EJO (1995c) Strandings of killer whales Orcinus orca in the Netherlands between 1783 and 1995 with some remarks on skeletal and dental pathology (Mammalia, Cetacea, Odontoceti). Deinsea 2:67-82

Kompanje EJO (1999) Considerations of the comparative pathology of the vertebrae in Mysticeti and Odontoceti: evidence for the occurrence of discarthrosis, zygarthrosis, infectious spondylitis and spondyloarthritis. Zool Med Leiden 73:99-130

LeCouteur RA, Grandy JL (2010) Diseases of the spinal cord. In: Ettinger SJ, Feldman EC (eds) Textbook of veterinary internal medicine, Vol 2. Expert Consult, ST. Louis, MO (www.expertconsultbook.com, accessed 15 Oct 2012)

Mazzuca L, Atkinson S, Nitta E (1998) Deaths and entanglements of humpback whales, Megaptera novaeangliae, in the main Hawaiian Island, 1972-1996. Pac Sci 52:1-13

> Moore MJ, Early GA (2004) Cumulative sperm whale bone damage and the bends. Science 306:2215

Moore M, Knowlton AR, Kraus SD, McLellan WA, Bonde RK (2004) Morphometry, gross morphology and available histopathology in North Atlantic right whale (Eubalaena glacialis) mortalities (1970-2002). J Cetacean Res Manag 6:199-214

> Morton B (1978) Osteomyelitis (pyogenic spondylitis) of the spine in a dolphin. J Am Vet Med Assoc 173: 1119-1120

Nishiwaki M, Kasuya T (1971) Osteological note of an Antarctic sei whale (Balaenoptera borealis). Sci Rep Whales Res Inst Tokyo 23:83-89

> Ogden JA, Conlogue GJ, Light TR, Sloan TR (1981) Fractures of the radius and ulna in a skeletally immature fin whale. J Wildl Dis 17:111-116

Omura H, Kasuya T, Kato H, Wada S (1981) Osteological study of the Brydes whale (Balaenoptera edeni) from the central south Pacific and eastern Indian ocean. Sci Rep Whales Res Inst Tokyo 33:1-26

Osmond MG, Kaufman GD (1998) A heavily parasitized humpback whale (Megaptera novaeangliae). Mar Mamm Sci 14:146-149

Paterson R, Van Dyck SM (1996) Perinatal skeletal injuries in two balaenopterid whales. Mem Queensl Mus 39: 333-337

Patterson IAP, Reid RJ, Wilson B, Grellier K, Ross HM, Thompson PM (1998) Evidence for infanticide in bottlenose dolphins: an explanation for violent interactions with harbour porpoise? Proc R Soc Lond B Biol Sci 265: 1167-1170

Pfeiffer CJ (2009) Whale lice. In: Perrin WF, Würsig B, Thewissen JGM (eds) Encyclopedia of marine mammals. Academic Press, San Diego, CA, p 1220-1223

Philo LM, Hanns C, George JC (1990) Fractured mandible and associated oral lesions in a subsistence-harvested bowhead whale (Balaena mysticetus). J Wildl Dis 26: $125-128$

Rosenberg AE (2005) Bones, joints, and soft tissue tumors. In: Kumar V, Abbas AK, Fausto N (eds) Robbins and Cotran pathologic basis of disease. Elsevier, Philadelphia, PA, p 1273-1324

Ross HM, Wilson B (1996) Violent interactions between bottlenose dolphins and harbour porpoises. Proc R Soc Lond B Biol Sci 263:283-286

Simões-Lopes PC, Menezes ME, Ferigolo J (2008) Alterações senil-degenerativas, patológicas, traumáticas e malformações ósseas. In: Filho ELAM, Monteiro KDKA (eds) Biologia, ecologia e conservação do boto-cinza. Páginas \& Letras Editora e Gráfica, São Paulo, p 39-50

Slijper EJ (1936) Die Cetaceen vergleichend anatomisch und systematisch. Capita Zool VI 7:1-590

Slijper EJ (1946) Comparative biologic-anatomical investigations on the vertebral column and spinal musculature of mammals. Verh Kon Nederl Akad Wetensch Amsterdam II 42:1-128

Stede M (1994) Zur Todesursache bei Walen der niedersächsischen Nordseeküste. Drosera 94:7-19

Sweeny MM, Price JM, Jones GS, French TW, Early GA, Moore MJ (2005) Spondylitic changes in long-finned pilot whales (Globicephala melas) stranded on Cape 
Cod, Massachusetts, USA, between 1982 and 2000. J Wildl Dis 41:717-727

Thompson K (2007) Bones and joints. In: Maxie MG (ed) Jubb, Kennedy \& Palmer's pathology of domestic animals, Vol 1. Saunders, Philadelphia, PA, p 1-184

Turnbull BS, Cowan DF (1999) Synovial joint disease in wild cetaceans. J Wildl Dis 35:511-518

Turner (1871) On the so-called two-headed ribs in whales and in man. J Anat Physiol 5:348-361

Van Bree PJH, Nijssen H (1964) On three specimens of

Editorial responsibility: Michael Moore,

Woods Hole, Massachusetts, USA
Lagenorhynchus albirostris Gray, 1846 (Mammalia, Cetacea). Beaufortia 11:85-93

Wedekin LL, Engel MH, Azevedo A, Kinas PG, Andriolo A, Simões-Lopes PC (2010) Density and abundance of the humpback whale in the Brazilian breeding ground (stock A): aerial survey, 2008. Document SC/62/SH28, 30 May-11 June 2010, Scientific Committee of the International Whaling Commision, Agadir

Wilson JW, Kurtz HJ, Leipold HW, Lees GE (1979) Spina bifida in the dog. Vet Pathol 16:165-179

Submitted: March 8, 2012; Accepted: August 14, 2012 Proofs received from author(s): October 16, 2012 